\title{
QUERO APRENDER A LER E ESCREVER PARA DEIXAR DE SER SOMBRAS DOS OUTROS
}

\author{
I WANT TO LEARN HOW TO WRITE AND READ SO I CAN STOP LIVING \\ IN SOMEONE ELSE'S SHADOWS. \\ QUIERO APRENDER A LEER Y ESCRIBIR PARA DEJAR DE SER \\ "SHADOWS" DE OTROS
}

Fábio Falcão Oliveira ${ }^{1}$

De: Oliveira Fábio < $\underline{\text { oliveira.unemat@gmail.com> }}$

\section{RESUMO}

O presente artigo tem como finalidade apresentar como Paulo Freire ver a educação. Levando em consideração que a obra de Paulo Freire é gigantesca, apenas abordaremos alguns aspectos de suas obras. Mas o importante é ressaltar a necessidade de reflexão deste tema na atualidade brasileira, por este motivo, iremos confrontar a postura do governo de Jair Bolsonaro diante das ideias de Paulo Freire. Por final, lembraremos que a maneira como se trata a educação no Brasil é mostrada com desdém e entendemos que se não pensarmos sobre essas questões poderemos uma prática de consciência que é necessária para o desenvolvimento na nação.

Palavras Chaves: Educação; Paulo Freire; Autonomia; Consciência.

Abstract: The purpose of this article is to present how Paulo Freire sees Education. Considering that his work covers several areas we will only approach some aspects of it. It is very important to emphasize the need for thought and reflection on this subject in the current scenario in Brazil, for this reason, we will confront the governments posture of Jair Bolsonaro in face of Paulo Freire's ideas. Finally, reminding how disdainfully education is treated in Brazil and understanding that if we don't think about these issues we will lose the practice of awareness that is necessary for the development of the nation.

Keywords: Education; Paulo Freire; Autonomy; Conscience.

\section{RESUMEN}

Este artículo tiene como objetivo presentar cómo Paulo Freire velaeducación. Teniendoencuenta que la obra de Paulo Freire es gigantesca, sólo abordaremos algunos aspectos de sus obras. Pero lo importante es destacar lanecesidad de reflexionar sobre este tema en Brasil hoy, por esta razón, enfrentaremos laposicióndelgobierno de Jair Bolsonaro ante lasideas de Paulo Freire. Finalmente, recordaremos que la forma en que se trata laeducaciónen Brasil se muestracondesdén y entendemos que si no pensamos enestos temas podemos una práctica de conciencia que es necesaria para eldesarrolloenlanación.

Palabras clave:Educación; Paulo Freire; Autonomía; Conciencia.

\section{INTRODUÇÃO}

O presente artigo tem como finalidade pensar no papel da educação na sociedade brasileira. Com isso exploraremos algumas das ideias de Paulo Freire, é claro que não

\footnotetext{
${ }^{1}$ Pós-doutorado em Estudos Literários na UNEMAT, Doutor em História da Educação pela UFSCAR, Mestre em História da Educação (UNIMEP) e Licenciado em Filosofia (UNIMEP). Orcid: https://orcid.org/0000-0002-4648-9548. Email: oliveira.unemat@gmail.com/atelc_off@hotmail.com
} 
vamos conseguir abarcar todas elas, mas, o objetivo é apresenta como a educação e a autonomia é necessário para o desenvolvimento de uma práxis pedagógica.

A proposta é perceber o esforço de Paulo Freire em levar caminhos para pensarmos os processos educativos como necessário para formar uma conscientização. Apreender sobre o mundo em sua volta torna-se motor para viabilizar o olhar do indivíduo diante do mundo que está inserido.

Paulo Freire entende que a recuperação da razão se dá pelo processo de uma prática libertadora da educação. Transmitir conhecimento é a possibilidade de retirar os individuo da escuridão dando as condições de conhecer o mundo-em-si.

Isso é claro na proposta freiriana de educação que tem como perspectiva alcançar os excluídos na sociedade e oferecer maneiras de conscientização. Rigorosamente a prática da educação leva a recuperação da estima dos indivíduos, mostrando o caminho da humanização.

Além disso, mostraremos como o governo de Bolsonaro promove um antiintelectualismo quase que beirando ao fascismo, ou por pode-se dizer que é uma maneira de fascismo/neofascismo, em luta contra a educação brasileira. A ideia apresentada pela atual gestão federal é o propósito de governar por via de ataques ao símbolo máximo da educação no Brasil, a saber, Paulo Freire. Com isso as instituições também sofrem esses ataques e são alvos do autoritarismo descarado do governo.

Que descabidamente ofende as instituições brasileira no país e de forma pouco politizada, apresenta um autoritarismo que chega à beira de um antiintelectualismo. Sempre quebrando o processo de democratização, a cartilha de Bolsonaro é acometer Paulo Freire e as instituições educativas brasileira.

Aqui apresentaremos algumas reflexões sobre esse caminho apresentado e tentaremos pensar sobre isto, levando em consideração o indivíduo que, a beira deste processo opressor, necessita de uma pedagogia da libertação. Por isso a necessidade de pensar uma educação enquanto prática atual e perspectiva para mudança.

\section{I - PAULO FREIRE: EDUCAÇÃO E SENSIBILIDADE}

No dia 16 de abril de 2012, foi publicado no Diário Oficial a Lei 12.612 que transforma Paulo Freire no Patrono da Educação Brasileiro (BRASIL, 2012). Paulo Freire é grande ícone da educação do Brasil e sua representatividade reconhecida, pois 
foi condecorado com 48 títulos de Doutorados honoris causa e várias homenagens em universidade no exterior e no Brasil.

Autor respeitado no mundo, Paulo Freire começa realmente ser perseguido no dia 31 de março de $1964^{2}$. Neste ano, ele estava em Brasília envolvido com o Programa Nacional de Alfabetização (PNA) e o movimento golpista se torna forte, treze amigos renunciaram em coletiva seus mandatos. Freire não pôde fazê-lo por causa do envolvimento com o PNA e foi destituído da sua função, perdendo o cargo de Conselheiro pelo Decreto n. 942, de 20 de abril de 1964, homologado pelo ViceGovernador Paulo Guerra, porque o Governador Miguel Arraes já estava preso pelas forças no poder (FREIRE, 1996, p. 35).A esposa de Paulo Freire relata que:

Paulo falava em educação social, falava na necessidade de o aluno, além de se conhecer, conhecer também os problemas sociais que o afligiam. Ele não via a educação simplesmente como meio para dominar os padrões acadêmicos de escolarização ou para profissionalizar-se. Falava da necessidade de se estimular o povo a participar do seu processo de emersão na vida pública engajando-se no todo social. (FREIRE,1996, p. 36)

Essa ideia de uma educação social, que falava dos problemas sociais que os alunos deveriam conhecer e que mostrava uma necessidade para alfabetizar o povo pobre, leva desconfiança diante do discurso autoritário da ditadura militar que se enraíza naquela época. Os padrões acadêmicos, a escolarização, a forma como se profissionalizava os indivíduos o estimulou a criar uma maneira de ver o mundo.

Segundo a autora, Paulo Freire conseguiu traduzir a necessidade de seu tempo, eram anseios de uma parte da sociedade da década de 50 que galgava por uma mobilização, para refletir sobre a política e as mudanças sociais. Ele fazia parte do segmento progressista da sociedade brasileira composto pelo clero católico, pelos professores universitários, estudantes, operários, campesinos, intelectuais ou não que estavam dispostos a pensar (FREIRE, 1996).

A proposta da pedagogia educativa de Paulo Freire para essa época, basicamente era conseguir uma percepção clara da cotidianidade discriminatória da sociedade elitista, patriarcal e hegemônica. Para ele, educação como ato político só teria efeito se romper com as tradições arcaicas, autoritária, discriminatórias, elitistas e interditadoras fixada no governo brasileiro.

\footnotetext{
${ }^{2}$ Segundo Freire (1996, p. 35): "Foi como Relator da Comissão Regional de Pernambuco e autor do relatório intitulado "A Educação de Adultos e as Populações Marginais: O Problema dos Mocambos", apresentado no II Congresso Nacional de Educação de Adultos em julho de 1958, no Rio de Janeiro, que Paulo Freire firmou-se como educador progressista".
} 
O que chama atenção em Paulo Freire que, muitos tentaram solucionar o problema por via da economia, mas ao contrário dos outros, ele se indignava com a pobreza, com as injustiças sociais, com o analfabetismo e para este autor, apenas o educador e a educação poderiam fazer a diferença (FREIRE, 1996).

Segundo Freire (1967) na obra Educação como prática da Liberdade, pode-se fazer a leitura da sociedade em 3 viés práticos ao qual é apresentado no livro. $\mathrm{O}$ primeiro capítulo A Sociedade Brasileira em Transição fala sobre os poderes e as disputas políticas na década de 60, o segundo capítulo Sociedade Fechada e Inexperiência Democrática tem por argumento observar o momento histórico do golpe de Estado, o terceiro capítulo Educação Versus Massificação fala como pode ser concebido a sua proposta pedagógica e confronta a pedagogia da década de 60, ao qual era tradicional e por fim, Educação e Conscientização ele apresenta experiências educativas e como poderia desenvolver um método de alfabetização que alcance a todos e principalmente os adultos. Nesta obra ele argumenta que:

Educação que, desvestida da roupagem alienada e alienante, seja uma força de mudança e de libertação. A opção, por isso, teria de ser também, entre uma "educação" para a "domesticação", para a alienação, e uma educação para a liberdade. "Educação" para o homem-objeto ou educação para o homem-sujeito. (FREIRE, 1967, p. 36)

A prática educadora deve ser desvestida da roupagem alienada e alienante, ela é maneira e caminho para libertação. Ela é ferramenta para alcançar a liberdade e a educação criando um agente que protagoniza o papel do sujeito crítico. Seria um sujeito do seu tempo e que se propõe superar a domesticação imposta pelos disparato políticos e intencionais de uma elite mal-intencionada.

Nesta obra, uma frase nos chama atenção e que inclusive, ajudou-nos a pensar no título deste artigo, para entendermos o porquê, vamos contextualizar. Na década de 1960, Paulo Freire ensaiou algumas entrevistas com os grupos populares, para entender a diferença de classe da sociedade, compreender e explicar os fatos sociais que os homens se envolvem.

Essas entrevistas revelaram anseios, frustações, descrenças, os fantasmas dos grupos populares, as esperanças e também momentos estéticos da linguagem do povo, ele percebeu a maneira de como eles se expressavam por via da linguagem.

Em Arquivos do Serviço de Extensão Cultural da Universidade de Recife, encontrou depoimentos das áreas rurais e urbanas do Nordeste e do Sul do País. E entre as entrevistas, uma analfabeta nos chama atenção pela maneira linguística que retrata 
sua vida, segue a citação: “Quero aprender a ler e a escrever”, disse uma analfabeta do Recife, “"para deixar de ser sombra dos outros"” (FREIRE, 1967, p. 112).

De forma rápida, queremos destacar o símbolo da "sombra" falado por essa anônima a Paulo Freire, além de ter ser uma imagem muito forte, ela é vista e interpretada de diversas maneira em várias culturas no mundo. Mostra-nos Brandão (1986), na sua obra Mitologia Grega - Vol I, por exemplo, que entre os gregos a sombra está diretamente ligado ao ato de morrer. O sentido da morte apresenta-se como o ato de ocultar-se, ser como sombra, uma vez que na Grécia o morto cai na sombra do esquecimento.

Segundo Brandão (1986) quando uma pessoa morria na Grécia antiga, se dirigia para o Hades, a psiqué e o eídolon (a ideia) torna-se sombra, uma imagem pálida e inconsistente, abúlica, destituída de entendimento, sem prêmio ou castigo próprio.

Exatamente o contrário sucede com os homens da idade de bronze e a maioria dos heróis da idade que tem seu nome: após a morte, são lançados no Hades, onde, semelhantes à fumaça, se convertem em mortos anônimos, sem direito a honras ou a culto, por parte dos vivos. Hesíodo não fala em penas, em tormentos, mas só pelo fato de se transformarem em mortos anônimos, sem nenhum direito a culto, fica subentendido que "essas sombras" nada mais são que uma fumaça esquiva, o que se constitui, para o pensamento grego, no maior dos castigos, o deixar de ser. (BRANDÃO, 1986, 145)

Quando observamos o depoimento emocionante da analfabeta a Paulo Freire, se intencionalmente não sabemos, mas constata-se uma profunda comiseração no relato, ela resgata o sentimento de humanização no desejo que tem em aprender a ler e escrever: “Quero aprender a ler e a escrever”, disse uma analfabeta do Recife, “"para deixar de ser sombra dos outros"” (FREIRE, 1967, p. 112).

Neste sentido, Paulo Freire nunca negou que aprende com os educandos e nisto, ele categoricamente comunga com esta fala e organiza uma proposta para retirar as pessoas analfabetas das sombras para se tornarem visíveis na sociedade.

E como se recupera a razão? Como se pode sair das sombras? Na mitologia grega a sombra é apática, mas, o herói pode por instantes recuperar a razão mediante aos rituais apresentado no canto XI da Odisséia. Somente assim, Aquiles recupera o entendimento e poderia dialogar com Ulisses e transmitir o conhecimento de outra vida $^{3}$.

\footnotetext{
${ }^{3} \mathrm{O}$ ritual apresentado na mitologia grega consistia, segundo Brandão (1986, p. 130): "A conselho de Circe, Ulisses vai ao país dos Cimérios, às bordas do Hades, para consultar a alma do adivinho cego Tirésias acerca de seu regresso a Ítaca. Ulisses não desceu à outra vida. Abriu um fosso e o fez em torno das três libações a todos os mortos com mel, vinho e água, espalhando por cima farinha de cevada. Após
} 
Usando o mito como metáfora, Paulo Freire apresenta essa possibilidade de recuperação da razão, para retirar os indivíduos desfavorecidos da sociedade das sombras e o ritual para isso, diferente da Grécia antiga, é uma prática educativa que consiste, rigorosamente no dever sincero do educador. Isso se devemos considerar, apresentação de uma necessidade de recuperar os indivíduos levando, os mesmo, a uma humanização e libertação da alienação.Mas como fazer isso no atual Governo? Essa pergunta é de difícil resposta, pois o ataque do governo a Paulo Freire é frequente como vamos apresentar.

\section{II - PAULO FREIRE: EDUCAÇÃO ATUALIDADE E PERSPECTIVAS}

Quando pensamos no atual governo, a gestão de Jair Bolsonaro, percebemos as várias divergências que o governo tem proporcionado no Brasil no campo educativo. Porém, neste momento, vamos apenas olhar aos aspectos configurativos das mudanças radicais que o governo proporcionou à Educação, isto é, as investidas, ao qual podemos chamar de militância contra Paulo Freire e sua forma de pensar o mundo.

Com 55, $13 \%$ dos votos, Bolsonaro foi eleito no segundo turno à presidência do Brasil, mas isso já era um prenúncio do que haveria de vir. Almeida (2019) publica uma pesquisa intitulada Bolsonaro Presidente: Conservadorismo, evangelismo e a crise brasileira e desenvolve uma tese que perspectiva 3 pontos importantes para analisar o atual governo. Para este momento, o ponto que nos chama mais atenção, no universo da pesquisa de Almeida (2019) é como ele articula algumas ideias, que tinha como finalidade perspectivar o plano da mobilização nas ruas e redes sociais/digitais como estratégia para a eleição de Jair Bolsonaro.

Ele percebe que a mobilização para eleger Jair Bolsonaro, só teria efeito se passasse pelo mundo virtual, onde o verdadeiro engajamento de oralidade, ainda que fraca, pudessem se manifestar nas redes midiáticas. $\mathrm{O}$ debate nas redes mediáticas levava a pouca oralidade dos interlocutores e deixava claro uma militância virtual do conservadorismo de extrema direita. Além disso, os Fakes News, os memes, Fecebook, o Wathsapp, antilulismo, o discurso que o PT ajudou a derrocada do Brasil, a fala que ele estaria lutando contra corrupção do PT, foi um carro chefe para chegar a sua eleição (ALMEIDA, 2019).

evocar as almas dos mortos, degolou em cima do fosso duas vítimas pretas: um carneiro e uma ovelha, dádivas de Circe. 'O negro sangue correu e logo as almas dos mortos, subindo do Hades, se ajuntaram'. Pôde assim Ulisses conversar com sua mãe, Anticléia, com Tirésias, Aquiles e com vários outros heróis e heroínas". 
Um governo acostumado a implementar engodos na sua forma de atuar politicamente, usou seu plano de governo para começar a atacar a Educação no Brasil, e com isso, difere golpes contra o maior símbolo da educação na América do Sul, Paulo Freire.

Devemos ressaltar que o governo Bolsonaro apresenta uma proposta de discurso que ultrapassa a fronteira da democracia. Existe uma discussão onde muitos ainda não sabem caracterizar o governo de Bolsonaro, não sabemos se é fascista ou neofascista, mas longe da democracia, apresenta formar autoritárias que beiram essas duas vertentes apresentadas e namora a ditatura militar como se fosse a solução para os problemas brasileiros. O comportamento do Presidente e de seus comandados tem chamado atenção do mundo, além de atacar os direitos humanos ataca a educação, as comunidades LGBT+, as ONGs, pessoas que discordam e professores de filosofia e sociologia.

No dia 24 de setembro de 2019, o senhor Bolsonaro foi discursar na Assembleia Geral da ONU e quebrou um protocolo brasileiro de ser amistoso e honesto com outros países. Em tom ameaçador chamou de falácia a maneira como os outros líderes mundiais pensam na floresta Amazônica enquanto patrimônio da humanidade e chamou os países, que se posicionaram contra as queimadas da floresta, de terem espírito colonizador e até mesmo oferecer meios para que isso acontecesse. Como se não bastasse, falou que o Brasil estava à beira do Socialismo e atacou, com tom de agressividade, países como Cuba e Venezuela (BULLA et al, 2019).

Recentemente, houve uma manifestação que defendia a intervenção militar, convocando o AI - 5, criticava o Supremo Tribunal Federal (SFT) e o Congresso Nacional. Apesar do presidente Jair Bolsonaro negar que não tinha intenção antidemocrática, diante desta situação e questionado se poderia haver um golpe militar, ele enfatiza em discurso que ele já estava no poder e nunca pensou nisso: "Eu já estou no Poder. Já sou o presidente da República" (SOARES, 2020).É claro, contextualizando a frase, ele estava falando que não podia estabelecer um golpe militar contra ele mesmo, e até ofendeu aqueles que conspiram contra ele, como pessoas de falta de inteligência.

Mas o que nos chama atenção é a maneira arrogante que ele se expressou quando falou do cargo que exerce na República Federativa do Brasil - "Já estou no Poder" -, ele esqueceu que não é ele que está no poder, isso ele tem que entender, é o povo que democraticamente tem o direito de governo. Frases como essas inundam o 
universo político brasileiro no governo Bolsonaro e mostra estar à beira do fascismo ou, se não, à beira de um neofascismo.

Eduardo Bolsonaro, por exemplo, pediu a intervenção do AI-5 e argumentou que se a esquerda radicalizar eles precisariam de uma resposta ${ }^{4}$. Além disso, mostrando simpatia ao fascismo (ou para com o neofascismo), a DW noticiou este evento que participava o filho de Bolsonaro e juntamente com vários jornais no Brasil e no mundo, mostrou também que no dia 17/10 de 2019 o Secretário da Cultura, Roberto Alvim ${ }^{5}$, se envolvendo em uma polêmica. Ele teve a simpatia de escrever um discurso pautado na fala do líder nazista Joseph Goebbels, que foi companheiro e ministro de Adolf Hitler.

Como se não bastasse, o governo Bolsonaro investe pesado contra a autonomia das universidades, ferindo a democracia acadêmica e nomeando 6 reitores que não chegaram ao primeiro lugar nas eleições acadêmicas. Na reportagem de Moreno (2019), é constatado que de 12 oportunidades obteve-se o número de 6 indicações e nomeações do Presidente Jair Bolsonaro. E quando observamos os institutos federais por 5 vezes das 6 ocasiões o escolhido foi respeitado. E por 2 vezes entre 18 casos o MEC (Ministério da Educação) decide nomear pessoas fora da lista do processo eleitoral.

\footnotetext{
${ }^{4}$ Isso foi noticiado pela DW MADE FOR MINDS/Alemanha no dia 31 do dez. 2019. Citaremos na integra o jornal alemão DW MADE FOR MINDS e a fala de Eduardo Bolsonaro na integra: "Vai chegar um momento em que a situação vai ser igual à do final dos anos 60 no Brasil, quando sequestravam aeronaves, quando executavam-se e sequestravam-se grandes autoridades, cônsules, embaixadores, execução de policiais, de militares", afirmou Eduardo. "Se a esquerda radicalizar a esse ponto, a gente vai precisar ter uma resposta. E a resposta pode ser via um novo AI-5, via uma legislação aprovada através de um plebiscito, como aconteceu na Itália. Alguma resposta vai ter que ser dada", completou o filho do presidente Jair Bolsonaro. O Ato Institucional $\mathrm{n}^{\circ} 5$ (AI-5) foi editado em 13 de dezembro de 1968 pelo então presidente Artur da Costa e Silva, um dos cinco generais que governaram o país durante o regime militar (1964-1985). Em vigor até dezembro de 1978, a medida é considerada o maior símbolo da repressão política durante a ditadura, tendo fechado o Congresso Nacional e suspendido direitos políticos. ${ }^{5}$ Roberto Alvim mostra simpatia ao nazismo conforme noticiado pela DW; Segue a citação: "A arte alemã da próxima década será heróica, será ferrenhamente romântica, será desprovida de sentimentalismo e objetiva, será nacional com um grande pathos e será ao mesmo tempo imperativa e vinculante - ou não será", disse Goebbels no discurso, que é reproduzido em vários livros sobre o nazismo. O brasileiro afirmou Roberto Alvim: "A arte brasileira da próxima década será heróica e será nacional. Será dotada de grande capacidade de envolvimento emocional e será igualmente imperativa, posto que profundamente vinculada às aspirações urgentes de nosso povo, ou então não será nada". (DW MADE FOR MINDS, 17 de jan. de 2020)
} 


\section{Novos reitores das federais}

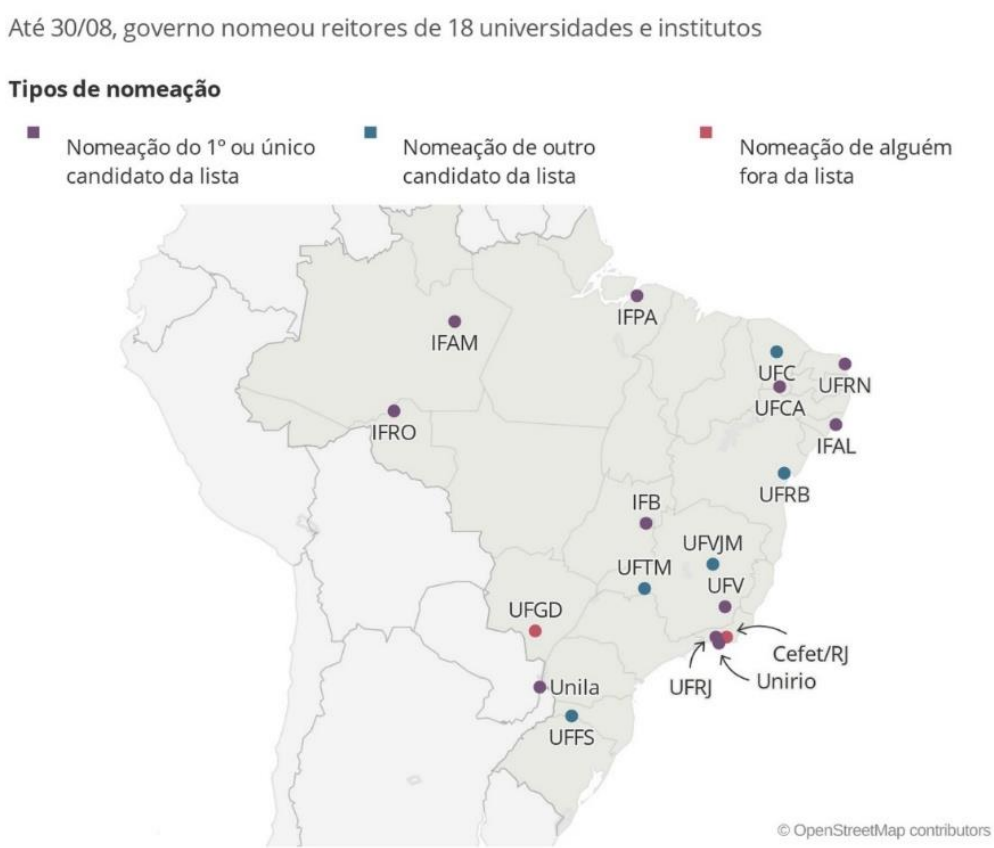

Mapa e lista de intervenções do Governo Bolsonaro (MORENO, 2019)

Segundo Ellen e Ferreira (2019) apesar do governo interferir diretamente na forma democrática como as universidades escolhiam seus reitores, o MEC negou interferência nas nomeações deixando o governo a mercê das decisões. O descaso vai além, em mais um vídeo publicado na internet, é mostrado Abraham Weintraub afirmando que os parlamentares auxiliavam na escolha do candidato para reitoria e com isso, garantiria que elas não sejam pessoas que promovem ideologias ${ }^{6}$.

Essas manifestações estranhas no Brasil podem ser entendidas à luz da obra de Stanley (2019), com título Como Funciona o Fascismo: A política de nós e eles. Nesta obra, mostra que, quando se estabelece um fascismo é necessário distinguir "nós" de "eles" e sempre se vai apelar para distinções políticas, étnicas, religiosas e raciais. Essa divisão é necessária para modelar uma forma de ideologia que trabalha na sua fixação na sociedade.

No Brasil o governo Bolsonaro tem trabalhado a maneira do fascismo/neofascismo, e para demonstrar isso, citamos Stanley (2019) que comprova que os políticos fascistas justificam as suas ideias aniquilando o bom senso histórico, algo comum no governo. Porém, o mais importante para fixar uma política fascista é a

\footnotetext{
${ }^{6}$ Segundo Ellen e Ferreira (2019): "Presidente da Comissão de Educação da Câmara, o deputado Pedro Cunha Lima (PSDB-PB) diz que há orientação no MEC sobre a escolha dos reitores. - Em conversa com o ministro Weintraub, ficou claro: se for um reitor que tenha uma linha ideológica, partidária e contra o governo, ou que faça uma oposição mais dura, de ligação com PT ou PSOL, ele vai segurar (a nomeação) — afirma".
} 
necessidade de reescrever a realidade distorcendo do que é real. Existe uma linguagem de idealização que concomitantemente, apresenta um antiintelectualismo e ataca as universidades e sistemas educacionais que poderia fornecer ideias críticas e firmes.

Não conseguimos ver outra coisa, quando o governo Bolsonaro fere a democracia das universidades brasileiras e as instituições de ensino a não ser, uma forma de fascismo/neofascismo que se enraíza de maneira escambada. A criação da irrealidade nas teorias de conspiração e notícias falsas para minar oposição torna-se marca do governo.

Para Freire (2002, p. 44), quando aceitamos a morte de nossa história, ou destruímos a educação, menos temos chances de perceber um novo amanhã implicando numa eternidade neo-liberal que permanecerá e mata a possibilidade de sonhar. Desproblematizando o tempo leva à morte histórica de um povo, de uma cultura, de um indivíduo, ele cai nas sombras.

A democratização tão necessária para "falar com" é ferida nesta investida do governo Bolsonaro que leva, ao que Freire (2002, p. 44) chama de "desconsideração total do ser humano", quer dizer, o "falar com" que é um processo democrático, neste caso não é ensaiado e é assassinado por via de uma desconsideração do governo.

Ter autonomia, conforme descrito por Freire (2002, p. 41) é "amadurecimento do ser para si, é processo, é vir a ser". Com isto, ele mostra que o sentido de um enraizamento de uma autonomia parte das experiências estimuladoras da responsabilidade em levar a todos respeitosa liberdade. A autonomia vai se construindo na experiência de várias maneiras de se estabelecer inúmeras decisões. Para ilustrar isso, ele lembra que uma criança tem que ter a oportunidade de assumir eticamente e responsavelmente suas decisões, fundamentalmente autônomas - ele que deve decidir de forma democrática.

As instituições de ensino e as universidades não tiveram chance de serem autônomas. As indicações e posses dos não eleitos pelo governo Bolsonaro rompem com a tradição do ensino no Brasil, esmagando e decretando a morte de sua história. Construir autonomia só é possível em respeito aos outros, se isso não acontecer, cai no campo do autoritarismo e fascismo, algo demonstrado de maneira clara pelo governo Bolsonaro.

Isso é demonstrado quando o governo cria MEDIDA PROVISÓRIA $N^{\circ} 914, D E$ 24 DE DEZEMBRO DE 2019. Edição:248-A,Seção: 1, que prevê o seguinte: 


\section{Escolha e nomeação dos reitores}

Art. $6^{\circ} \mathrm{O}$ reitor será escolhido e nomeado pelo Presidente da República entre os três candidatos com maior percentual de votação.

$\S 1^{\circ} \mathrm{Na}$ hipótese de um dos candidatos a reitor que componha a lista tríplice desistir da disputa, não aceitar a nomeação ou apresentar óbice legal à nomeação, a lista tríplice será recomposta com a inclusão de outros candidatos até completar o número de três e seguirá a ordem decrescente do percentual obtido na votação.

$\S 2^{\circ} \mathrm{O}$ reitor escolherá o vice-reitor dentre os docentes que cumpram os requisitos previstos no art. $4^{\circ}$, que será nomeado pelo Presidente da República para mandato para período coincidente ao do titular.

$\S 3^{\circ}$ Os demais ocupantes de cargos em comissão e funções de confiança na instituição de ensino serão nomeados ou, conforme o caso, designados pelo reitor. (BRASIL, MP, No 914/2019, 248-A, Seção 1)

Conseguimos perceber que a democratização das escolhas da comunidade acadêmica é atacada nesta MP 914/2019, as eleições são burladas e agora, um dos três candidatos, inclusive aqueles que menos voto recebeu, pode alcançar a reitoria conforma a necessidade ideológica e estratégico do governo Bolsonaro. No Art. $6^{\circ}$ a autonomia é destruída e a democracia recebe duros golpes quanto existe a intervenção do Presidente da República.

Além disso, é colocado de maneira intencional a regra Pro Tempore que, designa a autoridade máxima ao Ministério da Educação nomear cargos de vice-reitores e reitores quando, for impossível a homologação por qualquer questão, podendo assim estabelecer um processo de consulta. Segue o texto:

\section{Designação de reitor pro tempore}

Art. $7^{\circ} \mathrm{O}$ Ministro de Estado da Educação designará reitor pro tempore nas seguintes hipóteses:

I - na vacância simultânea dos cargos de reitor e vice-reitor; e

II - na impossibilidade de homologação do resultado da votação em razão de irregularidades verificadas no processo de consulta. (BRASIL, MP, No 914/2019, 248-A, Seção 1)

As mudanças impostas pela MP são vistas como retrocesso a construção histórica eleitoral que se firmou historicamente, e conforme o Conselho Nacional das Instituições da Rede Federal de Educação Profissional, Científica e Tecnológica (CONIF, 2019) é ato democrático a indicação do candidato vencedor em eleição de dirigentes-gerais ou reitores, mostrando os segmentos das comunidades e fortalece a instituição da Rede Federal de Educação Profissional, Científica e Tecnológica.

Portanto, o Conif repudia e considera indevido o teor de tal MP, visto que há uma legislação vigente e que o tema não atende aos pressupostos de admissibilidade - urgência e relevância - que justifiquem o ato da presidência da República, arranhando, dessa forma, o Estado Democrático de Direito. (CONIF, 26 de dezembro de 2019)

A nota de repúdio da Conif (2019) contra a Medida Provisória (MP) nº 914/2019, deixa claro que a forma como o governo escolhe para intervir nas instituições de ensino 
surge na contramão da democracia e fere a lei de criação dos institutos federais (Lei $\mathrm{n}^{\circ}$ 11.892/2008) e, de forma inadequada, se sobrepõe à autonomia das instituições.

Autonomia se estilhaça com a MP n 914/2019 e Renato Janine lembra que a Lei 11.892 previa que o reitor seria eleito de forma triparitária(um terço de professores, um terço de funcionários e um terço de alunos); ir contra isso é assumir o retrocesso proposto por Bolsonaro ao sistema educacional brasileiro (RBA, 2019).

Esse não é o único exemplo de ataque a educação, o maior símbolo da educação brasileira foi atacado por diversas vezes. Ricardo Vélez Rodriguez, o primeiro indicado por Jair Bolsonaro ao cargo do MEC (Ministério da Educação e Cultura), é mostrado por Fonseca (2019) como um homem que não se interessa por nada e a única sina é lutar contra Paulo Freire.

Segundo Neto, Teófilo e Bastos (2019), o ex-ministro Rodriguez deixou o cargo dia 30 de abril de 2019 e o novo sucessor parece não pensar diferente. Seguindo a cartilha de Bolsonaro, o novo ministro Abraham Weintraub anuncia corte de $30 \%$ das verbas de três universidades, Universidade de Brasília (UnB), Universidade Federal Fluminense (UFF) e a Universidade Federal da Bahia (UFBA). Para ele o dinheiro destinado a educação é usado para fazer bagunça e eventos ridículos. Com o Decreto $\mathrm{n}$. 9.741/2019 favoreceu o contingenciamento dos recursos bloqueando do orçamento estendendo os termos as universidades e institutos federais.

Além disso, estudou em fazer cortes nas áreas de Ciências Humanas atingindo principalmente os cursos de Filosofia e Sociologia, entendendo serem disciplinas de conteúdo de esquerda. Os ataques a universidades se insere no seu modelo antiintelectualista que ofende e fere o maior símbolo da educação brasileira, Paulo Freire. Empolgado com a postura de seu ministro, o governo Bolsonaro afirmou retirar o título de patrono da Educação brasileira dado à Paulo Freire (NETO; TEÓFILO e BASTOS, 2019).

Capriani (2019) mostra o descontentamento e a falta de intelectualidade de Abraham quando comenta que a cartilha freiriana é uma perda de tempo e fetiche da esquerda. Além disso, na matéria da Gazeta do Povo, do estado do Paraná, mostra entrevista de Abraham falando que Paulo Freire é um vodu sem comprovação científica nenhuma.

Em outra entrevista dada a Eduardo Bolsonaro, o ministro da educação Abraham cita "O Capital” de forma equivocada e faz críticas a Paulo Freire, inclusive, ambos abaixam o nível da entrevista partindo para ofensas: "Paulo Freire é tão ruim, tão ruim, 
tão ruim que ele bom, como a Dilma. É feio, é fraco, não tem resultado positivo e o pessoal quer defender. É bater em morto".

As barbaridades do governo são mostradas de maneira descarada pelo próprio Presidente do Brasil, Jair Bolsonaro, chamando Paulo Freire de "energúmeno" e ainda retirou a homenagem feita ao educador citado tirando seu nome da Plataforma CAPES (MAZIU, 2019). Certas perguntas surgem com esses ataques do governo Bolsonaro ao símbolo máximo da educação Brasileira.

Assim, nos resta pensar. Como podemos pensar na educação no Brasil? De que maneira podemos oferecer aos agressores uma forma de pensar sobre a prática docente? Por que o governo Bolsonaro prefere o embate do que o diálogo? Por que não oferecer a população brasileira maneiras para pensar na educação?

\section{III - EDUCAÇÃO, PRÁTICA DOCENTE E HUMILDADE}

O diálogo empolgante entre Paulo Freire e a anônima de Recife revela algo profundo quando ela diz: “Quero aprender a ler e a escrever”” (...) “"para deixar de ser sombra dos outros"” (FREIRE, 1967, p. 112). Talvez possamos ver isso como gatilho para reflexão sobre a consciência do outro nas obras de Paulo Freire. Imaginemos como ele se sentiu ao ouvir isso?

A necessidade que o indivíduo, analfabeto e excluído tem de sair das sombras é clara quando existe a necessidade de propagação da consciência. Esse depoimento, mostra um profundo sentimento dela, diante do mundo. A necessidade de ler e escrever é a inserção do sujeito no mundo da educação, no mundo político e até mesmo social, mas também é, em Paulo Freie tudo isso e muito mais; a profundidade da ideia freiriana é o indivíduo alcançar a consciência do próprio existir, da própria maneira de ser e compreender o mundo por si mesmo.

Neste sentido, o mundo é realidade a ser vivenciada pelo indivíduo que aprendeu a refletir e com isso sai das sombras. A prática pedagógica e libertária de Paulo Freire é a possibilidade de levar um universo de contatos que possibilite a prática da consciência e uma ética e universal.

Sobre a educação em Paulo Freire (1967), sabemos que na obra Educação Como Prática da Liberdade, ele parte da premissa de que o homem está inserido numa

\footnotetext{
${ }^{7}$ Entrevista concedida para Eduardo Bolsonaro e publicado como Eduardo Bolsonaro conversa com o Ministro da Educação Abraham Weintraub. Disponível em: https://www.youtube.com/watch?v=960ARO3e3M0.
} 
constante relação do "mundo com o mundo" (pessoais, impessoais, corpóreas e incorpóreas), isso significa dizer que o mundo é uma realidade para ele e enquanto "realidade objetiva" deve ser conhecida.

Diferente do que o governo Bolsonaro entende, Paulo Freire pensa em educação enquanto significado e maneira manifesta de dizer que o homem-em-si é um universo de contatos no mundo e com o mundo. O homem e sua relação com a realidade é o resultado de estar com ela e nela. Seus atos, segundo o autor, o fazem criar e recriar seu mundo, se humanizando, crescendo e formando enquanto ser. $\mathrm{O}$ homem e sua relação com os homens nos mostra um constante desafiar-se, alterar-se e criar-se que permite ser o que é (FREIRE, 1967).

Talvez a mais bela definição de educação esteja nesta obra que insistentemente citamos: “A educação é um ato de amor, por isso, um ato de coragem. Não pode temer o debate. A análise da realidade. Não pode fugir à discussão criadora, sob pena de ser uma farsa" (FREIRE, 1967, p. 97).

Existem várias formas para se definir a palavra educação, mas sabemos que esta palavra vem do latim educare e por vezes pode aparecer a palavra derivada educativo. Porém, ambas têm como premissa o significado de "conduzir" ou "orientar", mas em Freire (1967), percebemos o conceito de educação como ato de amor.

Na obra, Educação Como Prática da Liberdade, o pesquisador Weffort (1967) escreve uma apresentação com título de Educação e Política (Reflexões sociológicas sobre uma pedagogia da Liberdade), ele investiga Paulo Freire e constata que sua investida a favor de uma educação (enquanto ato de amor) começa no ano de 1962, na região mais pobre do Brasil, o Nordeste, com, então, 15 milhões de analfabetos para uma população de 25 milhões de habitantes.

Na cidade de Angicos, no Rio Grande no Norte, ele conseguiu alfabetizar 300 trabalhadores rurais em 45 dias no ano de 1962. Isso impressionou a imprensa internacional e a opinião pública que o apoiou entre 1963 e março de 1964. Desenvolveu cursos de capacitação para coordenadores de vários estados do Brasil como, Rio de Janeiro, São Paulo, Rio Grande do Norte, São Paulo, Bahia, Sergipe e Rio Grande do Sul; “atingindo a vários milhares de pessoas. O plano de 1964 previa a instalação de 20.000 círculos que já se encontravam capacitados para atender, durante este ano, a aproximadamente milhões de alfabetizados (30 por círculo, com duração de 3 meses cada curso)" (Weffort, 1967, p. 10). 
Segundo Weffort (1967), no antigo Estado de Guanabara, chegaram a se inscrever 6000 mil pessoas e assim, teve-se início a uma forma de alfabetização nacional que envolvia etapas que priorizava os setores urbanos e depois os setores rurais. Com o golpe militar em 1964, Freire foi preso por 70 dias e depois exilado.

Desde a ditadura militar ele é perseguido por instigar nos indivíduos prática reflexiva, e hoje não é diferente. Como podemos perceber, a sua prática docente, a educação estabelecida por Paulo Freire (2013) - na obra Extensão ou Comunicação? consistia na forma dialógica cuja finalidade era o ato de respeito ao próximo. Onde o professor e o aluno estabelecessem um diálogo problematizando o mundo em sua volta:

Se a educação é dialógica, é óbvio que o papel do professor, em qualquer situação, é importante. Na medida em que ele dialoga com os educandos, deve chamar a atenção destes para um ou outro ponto menos claro, mais ingênuo, problematizando-os sempre.(FREIRE, 2013, p.42)

Essa prática educativa que se inicia no ano de 1962, acaba sendo a marca de sua vida. Quando foi Secretário da Educação da cidade de São Paulo (1989 - 1991), no governo petista da prefeita Luíza Erundina, formou-se um livro de entrevistas concedidas por ele, chamado A Educação na Cidade. Nele acaba chamando atenção, igualmente como se lembra na obra Pedagogia da Autonomia, da importância de discutir o papel do Estado com a gestão de Luíza Erundina; mostra que encontrou as escolas da cidade de São Paulo em 1989 em condições de esquecimento. E a palavra que ele usa para relatar a condição das escolas no estado de São Paulo foi "Horrorização" - "ficou Horrorizado" (FREIRE, 2002, p. 20).

Por isso, esboça um pensamento na obra A Educação na Cidade: deve-se melhorar as condições das escolas para que haja necessidade de melhora da qualidade e é impossível não pensar no sistema escolar sem despertar a consciência do outro diante da situação precária (FREIRE, 1991).

Esse talvez seja o medo do governo atual, Paulo Freire elabora uma pedagogia de despertamento que nega o autoritarismo, e isso foi claro no ano de 1964 e também se pode constatar nos dias atuais. A educação apresentada por Freire parte do pressuposto de mudança da realidade dos educados para que haja reflexão crítica.

Segundo Fernandes (2019) a mudança da realidade entendida por Paulo Freire é o elemento fundamental para o indivíduo perceber a sua consciência e isso só é possível por via do ato solidário do outro. Somente assim, se combate o anonimato da consciência diante do mundo. 
O papel da consciência crítica é combater o desalinhamento entre o pensamento e a prática, que estão sujeitos à consciência, ao reconhecimento, e à agência. A necessária consideração a ser feita é que a emancipação que Freire discute é de uma natureza dupla: ela tem lugar na consciência do indivíduo (e/ou grupo) e, por meio da unidade teórica-prática dialética corporificada na práxis, também ocorre materialmente no desmantelamento direto de estruturas opressivas. Isto implica em um estado contraditório entre consciência e atividade antes da abolição da opressão e exploração. (FERNANDES, 2016, p. 485)

Paulo Freire (1991) entende que é nas classes populares que as dificuldades afloram, tanto os problemas qualitativos como os quantitativos em referência às condições educativas. E são as crianças pobres que recebem as escolas de má qualidade ou não tem acesso a elas. Por educação Paulo Freire (2002, p. 53) entende: “como prática estritamente humana jamais pude entender a educação como experiência fria, sem alma (...). Nem tampouco compreendi a prática educativa como experiência que faltasse o rigor que se gera a necessária disciplina intelectual”.

Educar é prática do diálogo, é relação social da instituição escolar com a comunidade, é diálogo entre aluno e professor: "Impossível pensar a prática educativa, portanto a escola, sem pensar a questão do tempo, de como usar o tempo para a aquisição do conhecimento, não apenas na relação educador-educando, mas na experiência inteira, diária, da criança na escola" (FREIRE, 1991, p. 46).

A sensibilidade de Freire (2002) é notória, pois na Pedagogia da Autonomia: saberes necessários à prática educativa, enfatiza que a prática pedagógica é a universalidade do homem. A natureza humana é algo impossível de se abandonar e sua marca é a ética universal. A ética universal é um conceito que apresenta a prática ética do ser humano enquanto natureza própria a ser adquirida. $\mathrm{O}$ relacionar-se com o mundo leva o ser humano a pensar na sua humanidade de forma mais profunda.

Para Paulo Freire (2002) a percepção que teve dos homens e mulheres o leva perceber a necessidade de um exercício constante a favor da produção e do desenvolvimento da autonomia por parte dos educadores, educandos e instituições da educação, algo que não temos visto no governo Bolsonaro. Por uma educação autônoma, entende Paulo Freire (2002, p. 41):

autonomia enquanto amadurecimento do ser para si, é processo, é vir a ser. Não corre em data marcada. É neste sentido que uma pedagogia da autonomia tem de estar centrada em experiências estimuladoras da decisão e da responsabilidade, vale dizer, em experiências respeitosas a liberdade. 
O que fica claro é que, no governo Bolsonaro, o respeito à democracia não existe, como já mostrado, ele escolhe os reitores das Universidades Federais e as pessoas que foram eleitas democraticamente são burladas. Nos parece que o governo atual não quer parar com isso, seguindo uma cartilha muito próximo do fascismo/neofascismo, faz como escrito por Stanley (2019).

Fazendo uma política que tem como perspectiva, sempre minar o discurso público, sempre tem como finalidade atacar os ícones da educação e desvalorizar a prática docente. $\mathrm{O}$ autor mostra que quando existe autoritarismo é impossível ter um debate inteligente, que respeite as diferentes perspectivas e que tenha precisão de realidade vivida (STANLEY, 2019).

Paulo Freire chama os interlocutores a dialogar e proporcionar a relação do ser com o mundo, proposta da prática docente, da práxis educativa que passar a levar o indivíduo a pensar em si mesmo e no outro em sua volta. Educação está ligada à humanidade, à reflexão e à docência que coincide no esteio da sua própria vida, numa retidão e ética, sem autoritarismo ${ }^{8}$ :

O preparo científico do professor ou da professora deve coincidir com sua correção ética, respeito aos outros, coerência, capacidade de viver e de aprender com o diferente, não permitir que o malestar pessoal ou a nossa antipatia com relação aos outros nos façam acusá-lo do que não fez são obrigações a cujo cumprimento devemos humilde, mas perseverantemente nos dedicar. (FREIRE, 2002, p. 10)

A sensibilidade de percebermos que não devemos permitir que o "mal-estar" pessoal venha prejudicar os outros, como docente devemos entender que ensinar é um ato histórico, ético e coerente. O profissional da educação é, antes de mais nada, comprometido socialmente e politicamente com a prática educativa vislumbrando a transformação das desigualdades. Os valores da condição humana são de responsabilidades do homem consciente e é algo que requer do educador na sua vida e prática no exercício da docência. Ser um sujeito que cultiva a ética universal é oferecer a sociedade uma ação educativo-crítica e transformadora. Ética entendemos como:

a função de um bom homem é uma boa e nobre realização das mesmas; e se qualquer ação é bem realizada quando está de acordo com a excelência que lhe é própria; se realmente assim é, o bem do homem nos aparece como uma atividade da alma em consonância com a virtude, e, se há mais de uma virtude, com a melhor e mais completa (ARISTÓTELES, 1991, p. 14).

\footnotetext{
${ }^{8}$ Stanley (2019, p. 37) mostra que: "A educação, portanto, representa uma grave ameaça ao fascismo ou se torna um pilar de apoio para a nação mítica. Não é de se espantar, então, que os protestos e confrontos culturais nos campi universitários representem um verdadeiro campo de batalha político e recebam atenção nacional. Há muita coisa em jogo".
} 
Ser virtuoso no que faz é exercício ético e cultivo da virtude. O trabalho que o homem faz em todas as instâncias, se fizer para o bem, recebe o título da atividade da alma. A ética é prática da virtude, e essa é atividade da alma. Atividade que se manifesta da realização do homem em consonância da busca pelo bem da Polis e dos indivíduos que nela habita (ARISTÓTELES, 1991).

A educação tem como finalidade última a busca do bem, não só de si, mas do próximo. A prática educativa se estabelece como trabalho de cultivo da virtude. É a relação do professor e aluno que se dá nestes pontos acima apresentado. Sem uma ética universal de respeito ao outro é impossível a prática docente, é impossível aprender com o diferente, é impossível ensinar.

Para Freire (2002) ensinar exige respeito aos saberes dos educandos. É o estabelecimento de uma ética universal que abrange não apenas o ressinto escolar, mas todas as instâncias de uma sociedade. E quando o professor pensa, coloca a escola no dever de respeitar o próximo, o aluno, a comunidade, os movimentos sociais, enfim, devemos discutir com eles a realidade concreta associado à disciplina, cuja realidade apresenta.

Educar é substantivamente formar. Divinizar ou diabolizar a tecnologia ou a ciência é uma forma altamente negativa e perigosa de pensar errado. De testemunhar aos alunos, às vezes com ares de quem possui a verdade, rotundo desacerto. Pensar certo, pelo contrário, demanda profundidade e não superficialidade compreensão e na interpretação dos fatos. Supõe a disponibilidade à revisão dos achados, reconhece não apenas a possibilidade de mudar de opção, de apreciação, mas o direito de fazê-la. Mas como não há pensar certo à margem de princípios éticos, se mudar é uma possibilidade de um direito, cabe a quem muda - exige o pensar certo - que assume a mudança operada. Do ponto de vista do pensar certo não é possível mudar e fazer de conta que não mudou. É que todo certo é radicalmente coerente. (FREIRE, 2002, p. 16)

Educar é formar e não divinizar ou diabolizar as ciências ou a tecnologia. Educar como vimos na citação é pensar certo e não rotular aqueles que não avançaram na reflexão. A probabilidade de uma ética universal é pensar sobre o que é certo, mas é também, ter a humildade de repensar a possibilidade de mudar de opção.

Nesta vertente, o professor é o espelho ético e formal, a educação nas suas mãos deve aparecer de forma competente para não divinizar um conceito ou diabolizar outro, ele deve ser humilde para educar e intervir na sociedade e as vezes, pensar nas probabilidades de mudança. 
Ele não é soberbo como a citação de Freire (2002) indica, como agente de mudança social ele deve estar à frente, reagindo com diálogo e assumindo a coerência do aprendizado junto com a sociedade, com a escola, com o indivíduo, com o morador de sua comunidade... A ética universal que esse profissional carrega possibilita ao aluno alcançar conhecimento e se transformar em agente de mudança junto com ele.

O professor tem como finalidade oferecer ao aluno e à comunidade que atua, um propósito reflexivo para formar cidadão autônomos que venha pensar sobre o mundo em sua volta. E ter autonomia é pensar de forma livre, entender a democratização das palavras enquanto ferramenta viva e eficaz para não criticar de forma maldosa aqueles que não alcançaram uma prática consciente (FREIRE, 2002).

O professor, enquanto propagador da educação é um ser testemunhal por si só. Ele testemunha as mudanças sócias, o desenrolar da história, as decisões políticas e diante desta condição, pensar é "pensar" de maneira reflexiva e correta dentro desta proposta testemunhal. Se ele reproduzir apenas o que vê, achando que ele está correto em seus pensamentos e tira do aluno, ou do indivíduo, a possibilidade de argumentar, isso é autoritarismo e está longe da democratização: "re-diz em lugar de desdizê-lo. Não é possível ao professor pensar que pensar certo, mas ao mesmo tempo pergunta ao aluno se sabe com quem está falando" (FREIRE, 2002, p. 16).

O autor entende isso porque a educação está inteiramente ligada a história de um povo, e essa história está em constante processo de construção. O pensar certo é a construção do diálogo que leva ao exercício de uma ética universal que alcança todos os homens. Quando a narrativa do interlocutor ou do professor é vazia, transforma os indivíduos em um recipiente a ser completo, e quanto mais os indivíduos se deixam encher de forma passiva mais longe está de sua conscientização, e isso se aplica também ao aluno.

Segundo entende Paulo Freire (2002), isso acontece porque a história de um povo se constrói e está em constante processo de construção. Para ele pensar certo a partir do diálogo é exercer uma prática docente crítica que leva ao aluno valores importantes para própria vida percebendo essa construção social. Educação que não é bancária e a narração não deve cair nesta armadilha:

A narração, de que o educador é o sujeito, conduz os educandos à memorização mecânica do conteúdo narrado. Mais ainda, a narração os transforma em "vasilhas", em recipientes a serem "enchidos" pelo educador. Quanto mais vai "enchendo" os recipientes com seus "depósitos", tanto melhor educador será. 
Quanto mais se deixem docilmente "encher", tanto melhores educandos serão. (FREIRE, 1987, p. 37)

Pensar no professor como ser ético universal e como cidadão consciente é entender que sua prática e trabalho é apresentar uma educação sem intensões autoritárias, sem falsas fórmulas ou trapaças, não é transforma os alunos em vasilhas.

Na Pedagogia do Oprimido, em especial, Freire (1987) mostra como o autoritarismo e desrespeito se apresentam; quando a educação proposta, transforma a narrativa que deveria ser para educar, em algo depositável e bancário. Esse conceito bancário - é tomado como inconciliação entre educador e educandos, e para romper esse vício é necessária a superação desta contradição:

A educação "bancária", em cuja prática se dá a inconciliação educador-educandos, rechaça este companheirismo. E é lógico que seja assim. No momento em que o educador "bancário" vivesse a superação da contradição já não seria "bancário". Já não faria depósitos. Já não tentaria domesticar. Já não prescreveria. Saber com os educandos, enquanto estes soubessem com ele, seria sua tarefa. Já não estaria a serviço da desumanização. A serviço da opressão, mas a serviço da libertação. (FREIRE, 1987, p. 40)

A maneira bancária de educar estabelece a adaptação da realidade ajustando os homens no modelo de realidade dada pelo educador. Quando mais se deposita narrativas no aluno, menos se sabe do mundo ou menos se tem consciência. A passividade domina o indivíduo e ele nada pode contribuir para sociedade que ele vive. Esta atitude bancária apenas satisfaz os opressores e torna os oprimidos mais oprimidos e sem humanização a visão de humanidade que eles têm é algo reproduzido levando-os a uma alienação da consciência.

É o reconhecimento da complexidade e as relações dialéticas que permite uma pedagogia problematizadora capaz de cultivar a consciência crítica, em oposição a uma visão estruturalista desumanizante que reifica pessoas reais de acordo com as funções de opressor e oprimido. (Fernandes, 2016, p. 484)

Segundo Paulo Freire, os sujeitos quando iniciam sua reflexão crítica, por via da dialética, abrem-se na direção de outros temas: "Esta abertura, que não existirá, no caso de seu conteúdo temático estar demasiado explicitado ou demasiado enigmático, é indispensável à percepção das relações dialéticas que existem entre o que representam e seus contrários" (FREIRE, 1987, p. 69).

Por esse motivo, a educação que problematiza se manifesta no esforço dos homens que querem sair das sombras e serem atuantes e conscientes diante do mundo que fazem parte se tornando sujeito ético. Por isso que para o governo atual, Paulo 
Freire como educador, autonomia universitária, democratização educativa são pontos perigosos pois, leva os indivíduos a pensarem e questionarem a realidade vivida.

Segundo Freire (2002), a ética universal do ser humano é uma ética que marca a natureza humana e passa ser algo impossível de ser abandonada. Envolver-se com os indivíduos e com o mundo é a tarefa da prática docente que resgata a humanidade do outro. Aquisição do conhecimento é prática do exercício da universalidade do homem.

Apresentar uma prática educativa e sincera é para Paulo Freire é oferecer condições para o outro pensar, por isso o discurso verdadeiro é importante para levar o aluno a uma reflexão ética e sem autoritarismo. Com isso, ele pede para que os professores(as) que tenham preparo científico para se opor à condição bancária e isso é um processo de respeito com a profissão e com a sociedade.

\section{CONCLUSÃO}

Como percebemos, a desenvoltura da prática libertadora de Paulo Freire nos mostra categorias educativas que são necessárias para pensarmos o cotidiano. $\mathrm{O}$ conhecimento prático no exercício de uma universalidade do homem é entendido como motor formador.

Prática essa que não se dá pelo autoritarismo ou sabotagem da educação, mas a proposta é uma maneira livre para se pensar as intervenções políticas, sociais e educativas no cenário brasileiro. Porque se houver autoritarismo se estabelece um caminho para morte da educação.

O governo Bolsonaro quando se nega dialogar com as diferenças apresenta um discurso autoritário pronto para assassinar a maior herança da educação brasileira. $\mathrm{O}$ legado freiriano é possibilidade de pensarmos na educação, uma educação libertadora que alcança os excluídos e ajuda o opressor a se reconhecer opressor.

Quando os ataques às instituições brasileiras começaram a se apresentar pelos comandados do governo, retira-se a expectativa de uma alfabetização crítica para aqueles que vivem nas sombras.

As instituições e o próprio professor são a esperança de uma nação que enfrenta problemas sociais, não existe na história da humanidade um povo que desprezou a educação e sobreviveu. No Brasil, Paulo Freire mostra que, o caminho para uma reflexão crítica só pode ser feito por via da dialogicidade e esta é campo da prática educativa.

Sem uma educação que reconhece a autonomia e a prática da democratização das instituições, não é possível o desenvolvimento do intelecto humano. Compreender 
está prática é necessário para formar os indivíduos que estão à margem da apreensão do mundo que vive.

As classes populares precisam de condições para alcançar a educação de maneira mais sincera e clara. Mas o que vemos no Brasil é ataque às universidades; as escolas periféricas são esquecidas e professores não são valorizados.

Com a prática educativa e humana pode-se alcançar uma ética universal que leve os indivíduos a experiências que o aperfeiçoe. Assim galgará um racionalismo que, por rigor, contribuirá para sua intelectualidade formadora.

A educação valoriza a história dos indivíduos. Educação como exercício da curiosidade e não arrogância intelectual, é nisso que a proposta de Paulo Freire pauta e podemos perceber toda estrutura da educação libertadora.

O confronto do governo brasileiro com Paulo Freire é o espelho da intolerância e da negação de uma importância crucial para formação dos homens. A maneira como o governo vê as instituições federais se mostra num processo indeciso, que não comporta o respeito nem o diálogo.

Finalmente, a organização programática de intervenções que o governo usa é a desconstrução educativa do Brasil e com isso, reformulam uma compreensão de autoritarismo que leva os indivíduos as sombras. Essa peleja proposta pelo governo contra Paulo Freire apenas define o favorecimento de um regime autoritário e militar e seu maior inimigo é uma educação dialógica, algo que se encontra em toda obra freiriana.

\section{Referências bibliográficas}

ALMEIDA, Ronaldo. "Bolsonaro Presidente: Conservadorismo, evangelismo e a crise brasileira”. In_: NOVOS ESTUDUDOS CEBRAP/SCIELO. Vol. 38, n. 1. São Paulo: CEBRAP/Scielo, abril de 2019.Disponível em: http://www.scielo.br/scielo.php?script=sci_abstract\&pid=S010133002019000100010\&lng=pt\&nrm=iso. Consultado dia 20 de março de 2020. ARISTÓTELES. Ética a Nicômaco(Coleção os Pensadores). Trad. VALLANDRO, Leonel e BORNHEIM, Gerd. - versão inglesa de W. D. Ross. São Paulo: Nova Cultura, 1991. Disponível em:http://abdet.com.br/site/wpcontent/uploads/2014/12/\%C3\%89tica-a-Nic\%C3\%B4maco.pdf. Consultado dia 20 de março de 2020. 
BOLSONARO, Jair. Eduardo Bolsonaro conversa com o Ministro da Educação Abraham Weintraub. Brasília: mimeo, 2 de março de 2019. Disponível em: https://www.youtube.com/watch?v=960ARO3e3M0. Consultado dia 20 de março de 2020.

BORGES, André e VIEIRA, Victor. "Nova MP de Bolsonaro Impõe restrições para eleição de Reitor em Universidades federais". In_: O ESTADO DE SÃO PAULO/EDUCAÇÃo ESTADÂO. São Paulo: Estadão 26 de dezembro de 2019. Disponível em: https://educacao.estadao.com.br/noticias/geral,bolsonaro-publica-mpcom-regras-para-escolher-reitores-de-universidades-federais,70003136197. Consultado dia 20 de março de 2020.

BRANDÃO, Junito de Souza. Mitologia Grega - Vol I. Petrópolis: Vozes, 1986.

BRASIL. DIÁRIO OFICIAL DA UNIÃO: LEI N 12.612, DE 13 DE ABRIL DE 2012/ATOS DO PODER LEGISLATIVO.Seção 1 - Extra. Brasília, Imprensa Nacional, 16 de abril de 2012. Disponível em: http://portal.mec.gov.br/index.php?option=com_docman\&view=download\&alias=1056 2-16-04-12-link-leipaulofreire\&category_slug=abril-2012-pdf\&Itemid=30192.

Consultado dia 20 de março de 2020.

DIÁRIO OFICIAL DA UNIÃO:MEDIDA PROVISÓRIA No 914, DE 24 DE DEZEMBRO DE 2019/ATOS DO PODER LEGISLATIVO. Edição: 248-A, Seção: 1 - Extra. BRASÍLIA: Imprensa Nacional. 24 de dezembro de 2019, página 7. Disponível em: http://www.in.gov.br/en/web/dou/-/medida-provisoria-n-914-de-24-dedezembro-de-2019-235278221. Consultado dia 20 de março de 2020.

BULLA, Beatriz et al. "Em discurso desafiador na ONU, Bolsonaro ataca ‘colonialismo' na questão”. In_: ESTADÃO/Política. São Paulo, Jornal o Estadão, 24 de setembro de 2019. Disponível em: https://politica.estadao.com.br/noticias/geral,emdiscurso-desafiador-bolsonaro-ataca-colonialismo-na-questao-ambiental,70003022863. Consultado dia 20 de março de 2020.

CAPRIANI, Juliana. "Ministro da Educação chama Paulo Freire de 'fetiche' e critica: ‘É ou não é feio de doer”". In_: JORNAL ESTADO DE MINAS - POLÍTICA. Minas Gerais: Jornal Estado de Minas, 02 de agosto de 2019. Disponível em: https://www.em.com.br/app/noticia/politica/2019/08/02/interna_politica,1074319/minist ro-da-educacao-chama-paulo-freire-de-fetiche-da-esquerda-e-feio.shtml. Consultado dia 20 de março de 2020. 
CONIF - Conselho Nacional das Instituições da Rede Federal de Educação Profissional, Científica e Tecnológica. NOTA SOBRE A MEDIDA PROVISÓRIA No 914/2019. Brasília: CONIF, 26 de dezembro de 2019.Disponível em: http://portal.conif.org.br/images/26_12_2019_nota_p\%C3\%BAblica_MP_914.pdf.

Consultado dia 20 de março de 2020.

DW MADE FOR MINDS/Alemanha. Fala de Eduardo Bolsonaro sobre AI-5 gera Indignação em Brasília. Brasil/Alemanha: Deutsche Welle, 31 do dez. 2019. Disponível em: https://www.dw.com/pt-br/fala-de-eduardo-bolsonaro-sobre-ai-5-geraindigna\%C3\%A7\%C3\%A3o-em-bras\%C3\%ADlia/a-51077897. Consultado dia 20 de março de 2020.

Secretário da Cultura cópia discurso de Ministro de

Adolf Hitler e gera polêmica. Brasil/Alemanha: Deutsche Welle, 17 de jan. 2020.

Disponível em emhttps://www.dw.com/pt-br/secret\%C3\%A1rio-da-cultura-copiadiscurso-de-ministro-de-hitler-e-gera-pol\%C3\%AAmica/a-52040824. Consultado dia 20 de março de 2020.

ELLER, Johanns e FERREIRA, Paula. "Maioria de reitores de universidades federais nomeados por Bolsonaro não venceu lista tríplice”. In_: O GLOBO SOCIEDADE.Rio de Janeiro: Globo.com, 22 de setembro de 2019. Disponível em: https://oglobo.globo.com/sociedade/maioria-de-reitores-de-universidades-federais-

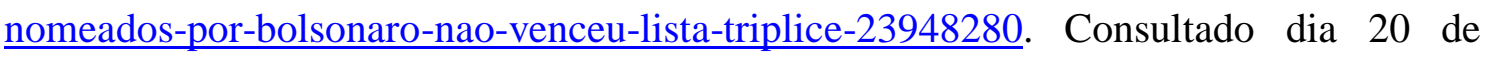
março de 2020.

FONSECA, Joel Pinheiro de. "A educação brasileira merece mais que a paranoia do MEC". In_: Revista eletrônica EXAME/Abril.com. São Paulo: Abril, 7 fev 2019. Disponível em: https://exame.abril.com.br/blog/joel-pinheiro-da-fonseca/a-educacao-brasileira-merecemais-que-a-paranoia-do-mec/. Consultado dia 20 de março de 2020.

FREIRE, Paulo. Educação Como Prática da Liberdade. São Paulo: Paz e Terra, 1967. Pedagogia do Oprimido. 17 Ed. São Paulo: Paz e Terra, 1987.

Disponível em: $\quad$ http://www.tlaxcala-int.org/upload/telechargements/150.pdf. Consultado dia 20 de março de 2020.

A Educação na Cidade. São Paulo: Cortez, 1991.

Pedagogia da Autonomia: saberes necessários à prática educativa. 25ª Ed. São Paulo; Paz e Terra/Impresso no Brasil, 2002. 
Extensão ou comunicação? [recurso eletrônico]. Trad. OLIVEIRA, Rosiska Darcy de. $1^{a}$ Ed.Rio de Janeiro: Paz e Terra, 2013. Disponível em: https://www.academia.edu/38319324/Paulo_Freire_-

_Extens\%C3\%A3o_ou_comunica\%C3\%A7\%C3\%A3o_pdf. Consultado dia 20 de março de 2020.

FREIRE, Ana Maria A. “A voz da esposa A TRAJETÓRIA DE PAULO FREIRE”. In_: GADOTTI, Moacir (org). PAULO FREIRE -Uma biobibliográfica. São Paulo: Cortez $\quad 1996 . \quad$ Dditora, Disponível em: http://acervo.paulofreire.org:8080/jspui/bitstream/7891/3078/1/FPF_PTPF_12_069.pdf. Consultado dia 20 de março de 2020.

FERNANDES, Sabrina. "Pedagogia crítica como práxis marxista humanista: perspectivas sobre solidariedade, opressão e revolução". In_: EDUC. SOC. v. 37, n. 135, Campinas: p. 481-496, $2016 . \quad$ Disponível em: https://www.scielo.br/pdf/es/v37n135/1678-4626-es-37-135-00481.pdf. Consultado dia 20 de março de 2020.

GAZETA DO POVO. ENTREVISTA ABRAHAM WEINTRAUB, Ministro da Educação: Paulo Freire é um VUDO. Paraná: Gazeta do Povo, 22 de novembro de 2029. Disponível em: https://www.youtube.com/watch?v=2Y2wrHSxs0k. Consultado dia 20 de março de 2020.

MAZUI, Guilherme. 'Bolsonaro chama Paulo Freire de 'energúmeno' e diz que TV Escola 'deseduca'”. In_:G1 POLÍTICA. Brasília: G1, 16 de dezembro de 2019. Disponível em: https://g1.globo.com/politica/noticia/2019/12/16/bolsonaro-chamapaulo-freire-de-energumeno-e-diz-que-tv-escola-deseduca.ghtml. Consultado dia 20 de março de 2020.

MORENO, Ana Carolina. "Governo Interveio em 6 de 12 nomeações de reitores de universidades federais até agosto". In_: REVISTA ELETRÔNICAG1 EDUCAÇÂO. Rio de Janeiro: Globo.com, dia 31 de agosto de 2019. Disponível em: https://g1.globo.com/educacao/noticia/2019/08/31/governo-interveio-em-6-de-12nomeacoes-de-reitores-de-universidades-federais-ate-agosto.ghtml. Consultado dia 20 de março de 2020.

NETO, Almir Magali; TEÓFILO, João e BASTOS, Sophia Pires. "Desmonte da Educação: o anti-intelectualismo no governo Bolsonaro". In_: Centro de Estudos sobre Justiça de Transição. Minas Gerais: UFMG informática JR, 5 de setembro de 
2019. Disponível em: https://cjt.ufmg.br/2019/05/09/desmonte-da-educacao-a-antiintelectualismo-no-governo-bolsonaro/. Consultado dia 20 de Março de 2020.

RBA - Rede Brasil Atual. "Janine sobre MP que muda eleição em entidades federais de ensino: 'Nem na ditadura foi assim"'. In_: RBA - REVISTA DO BRASIL/REDE BRASIL ATUAL/EDUCAÇÂO. São Paulo: Revista Brasileir, 27 de dezembro de 2019. Disponível em: https://www.redebrasilatual.com.br/educacao/2019/12/janine-sobre-mpque-muda-eleicao-em-entidades-federais-de-ensino-nem-na-ditadura-foi-assim/. Consultado dia 20 de março de 2020.

SOARES, Ingrid. "Bolsonaro: 'Já estou no poder. Então, estou conspirando contra quem'?”. In_: CORREIO BRASILIENSE/POLÍTICA. Brasília: Correio Brasiliense, postado em 20/04/2020. Disponível em: https://www.correiobraziliense.com.br/app/noticia/politica/2020/04/20/interna_politica, $\underline{\text { 846448/bolsonaro-ja-estou-no-poder-entao-estou-conspirando-contra-quem.shtml. }}$. Consultado dia 20 de abril de 2020.

STANLEY, Jason. Como Funciona o Fascismo: A política de nós e eles.Portugal: WOOK, 2019. Disponível em: https://www.wook.pt/livro/como-funciona-o-fascismojason-stanley/23166574. Consultado dia 20 de março de 2020.

WEFFORT, Francisco C. "Educação e Política(Reflexões sociológicas sobreuma pedagogia da Liberdade)". In_: FREIRE, Paulo. Educação Como Prática da Liberdade. São Paulo: Paz e Terra, 1967. 